Supporting Information

\title{
Versatile Double-Beam Confocal Laser System Combined with Fourier Transform Ion \\ Cyclotron Resonance Mass Spectrometer for Photodissociation Mass Spectrometry and Spectroscopy
}

Kailin Zhang ${ }^{1,2}$, Yingying Shi ${ }^{1}$, Mengying $D u^{1}$, Yicheng $X u^{1}$, Yan Wang ${ }^{2}$, Xianglei

Kong $1,3 *$

${ }^{1}$ State Key Laboratory of Elemento-organic Chemistry, Collage of Chemistry, Nankai

University, Tianjin, 300071, China.

${ }^{2}$ School of Precision Instrument and Opto-Electronics Engineering, Tianjin University, Tianjin 300072, China.

${ }^{3}$ Collaborative Innovation Center of Chemical Science and Engineering, Nankai University, Tianjin, 300071, China

Correspondence to Prof.X. Kong, E-mail: kongxianglei@nankai.edu.cn 


\section{Table of contents}

Table S1 Identification of the observed fragment ions in the experiments. Internal calibration was applied using the three ions of the $[\mathrm{M}+\mathrm{H}]^{+},\left[\mathrm{M}+\mathrm{H}-\mathrm{NH}_{3} \mathrm{I}\right]{ }^{\cdot+}$ and $\left[\mathrm{M}+\mathrm{H}-\mathrm{NH}_{3} \mathrm{I}_{2}\right]^{+}$.

Figure S1 A control experiment of the isolated ion $[\mathrm{M}+\mathrm{H}]^{+}$at $\mathrm{m} / \mathrm{z} 433.87$ to that corresponding to Fig. 2a, with both IR and UV lasers off.

Figure S2 Photodissociation mass spectra of $[\mathrm{M}+\mathrm{H}]^{+}$at $\mathrm{m} / \mathrm{z}$ 433.87, generated by UV-first sequential irradiation of both IR and UV beams, in which the trigger of the UV laser is (a) no, (b) $5 \mathrm{~s}$, (c) $10 \mathrm{~s}$, (d) $15 \mathrm{~s}$ and (e) $18 \mathrm{~s}$ delay to that of the IR laser.

Figure S3 Relative intensities of different fragment ions generated in different sequential experiments: (a) ions at $\mathrm{m} / \mathrm{z} 416.85$ and 387.87 , which can be generated by IRMPD; (b) ions at m/z 306.97, 289.94, 261.97 and 134.06; which can be generated by UVPD; (c) ions at $\mathrm{m} / \mathrm{z} 163.04$, which was generated by the IR irradiation of the UVPD fragment ions; (d) ions at $\mathrm{m} / \mathrm{z}$ 245.96, 243.94, 233.96, 119.05 and 107.05, which were generated by the UV irradiation of the IRMPD fragment ions; (e) ions at $\mathrm{m} / \mathrm{z} 219.84$, which was also generated by the UV irradiation of the IRMPD fragment ions; and (f) ions at $\mathrm{m} / \mathrm{z} 271.94$ and 247.93, which can be generated by both processes. Among these results, the curves with typical nonmonotonic declines might indicate the existence of two or more pathways for their generation.

Figure S4 Top-down mass spectra of [Ubiquitin $+11 \mathrm{H}]^{+}$, generated by the irradiation of (a) IR laser at $3370 \mathrm{~cm}^{-1}$, (b) UV laser at $213 \mathrm{~nm}$ and (c) a combination of the IR at UV laser.

Figure S5 (a) The whole ESI mass spectrum without isolation; (b) the isolation ion of $[\mathrm{M}+\mathrm{H}]^{+}$at $\mathrm{m} / \mathrm{z} 433.87$; (c) the IRMPD mass spectrum of $[\mathrm{M}+\mathrm{H}]^{+}$obtained at 3570 $\mathrm{cm}^{-1}$ with an irradiation time of $30 \mathrm{~s}$; (d) the isolated fragment ion of $\left[\mathrm{M}+\mathrm{H}-\mathrm{NH}_{3}\right]^{+}$at $\mathrm{m} / \mathrm{z}$ 416.85; (e) the $251 \mathrm{~nm}$ UVPD mass spectrum of the selected IRMPD fragment ion at $\mathrm{m} / \mathrm{z} 416.85$, resulting an $\mathrm{MS}^{3}$ spectrum; (f) the isolated fragment ion of $\left[\mathrm{M}+\mathrm{H}-\mathrm{C}_{3} \mathrm{NO}_{2} \mathrm{H}_{5} \mathrm{I}\right]^{+}$at $\mathrm{m} / \mathrm{z}$ 219.94; (g) the $251 \mathrm{~nm}$ UVPD mass spectrum of the fragment ion at $\mathrm{m} / \mathrm{z} 219.94$, resulting an clear $\mathrm{MS}^{4}$ spectrum. 
Table S1. Identification of the observed fragment ions in the experiments. Internal calibration was applied using the three ions of the $[\mathrm{M}+\mathrm{H}]^{+},\left[\mathrm{M}+\mathrm{H}-\mathrm{NH}_{3} \mathrm{I}\right]{ }^{\cdot+}$ and $\left[\mathrm{M}+\mathrm{H}-\mathrm{NH}_{3} \mathrm{I}_{2}\right]^{+}$.

\begin{tabular}{|c|c|c|c|c|}
\hline $\begin{array}{c}\text { Molecular } \\
\text { formula }\end{array}$ & $\begin{array}{c}\text { Loss } \\
\text { unit from } \\
{[\mathrm{M}+\mathrm{H}]^{+}}\end{array}$ & $\begin{array}{c}\text { Experimental } \\
\mathrm{m} / \mathrm{z}\end{array}$ & $\begin{array}{c}\text { Theoretical } \\
\mathrm{m} / \mathrm{z}\end{array}$ & $\begin{array}{c}\text { Error } \\
(\mathrm{ppm})\end{array}$ \\
\hline $\mathrm{C}_{9} \mathrm{O}_{3} \mathrm{H}_{7} \mathrm{I}_{2}^{+}$ & $-\mathrm{NH}_{3}$ & 416.8462 & 416.8485 & 6 \\
\hline $\mathrm{C}_{8} \mathrm{NOH}_{8} \mathrm{I}_{2}^{+}$ & $-\mathrm{CO}_{2} \mathrm{H}_{2}$ & 387.8674 & 387.8695 & 5 \\
\hline $\mathrm{C}_{9} \mathrm{NO}_{3} \mathrm{H}_{10} \mathrm{I}^{+}$ & $-\mathrm{I}$ & 306.9687 & 306.9705 & 5 \\
\hline $\mathrm{C}_{9} \mathrm{O}_{3} \mathrm{H}_{7} \mathrm{I}^{+}$ & $-\mathrm{NH}_{3} \mathrm{I}$ & 289.9433 & 289.9440 & 2 \\
\hline $\mathrm{C}_{9} \mathrm{O}_{3} \mathrm{H}_{6} \mathrm{I}^{+}$ & $-\mathrm{NH}_{4} \mathrm{I}$ & 288.9371 & 288.9362 & 3 \\
\hline $\mathrm{C}_{9} \mathrm{O}_{2} \mathrm{H}_{5} \mathrm{I}^{+}$ & $-\mathrm{NOH}_{5} \mathrm{I}$ & 271.9322 & 271.9334 & 4 \\
\hline $\mathrm{C}_{8} \mathrm{NOH}_{8} \mathrm{I}^{+}$ & $-\mathrm{CO}_{2} \mathrm{H}_{2} \mathrm{I}$ & 260.9623 & 260.9651 & 11 \\
\hline $\mathrm{C}_{7} \mathrm{O}_{2} \mathrm{H}_{5} \mathrm{I}^{+}$ & $-\mathrm{C}_{2} \mathrm{NOH}_{5} \mathrm{I}$ & 247.9339 & 247.9334 & 2 \\
\hline $\mathrm{C}_{7} \mathrm{O}_{2} \mathrm{H}_{4} \mathrm{I}^{+}$ & $-\mathrm{C}_{2} \mathrm{NOH}_{6} \mathrm{I}$ & 246.9262 & 246.9256 & 2 \\
\hline $\mathrm{C}_{8} \mathrm{OH}_{7} \mathrm{I}^{+}$ & $-\mathrm{CNO}_{2} \mathrm{H}_{3} \mathrm{I}$ & 245.9539 & 245.9542 & 1 \\
\hline $\mathrm{C}_{8} \mathrm{OH}_{5} \mathrm{I}^{+}$ & $-\mathrm{CNO}_{2} \mathrm{H}_{5} \mathrm{I}$ & 243.9382 & 243.9385 & 1 \\
\hline $\mathrm{C}_{7} \mathrm{OH}_{7} \mathrm{I}^{+}$ & $-\mathrm{C}_{2} \mathrm{NO}_{2} \mathrm{H}_{3} \mathrm{I}$ & 233.9550 & 233.9542 & 3 \\
\hline $\mathrm{C}_{6} \mathrm{OH}_{5} \mathrm{I}^{+}$ & $-\mathrm{C}_{3} \mathrm{NO}_{2} \mathrm{H}_{5} \mathrm{I}$ & 219.9363 & 219.9385 & 10 \\
\hline $\mathrm{C}_{9} \mathrm{O}_{3} \mathrm{H}_{7}^{+}$ & $-\mathrm{NH}_{3} \mathrm{I}_{2}$ & 163.0394 & 163.0395 & 1 \\
\hline $\mathrm{C}_{8} \mathrm{NOH}_{8}{ }^{+}$ & $-\mathrm{CO}_{2} \mathrm{H}_{2} \mathrm{I}_{2}$ & 134.0598 & 134.0606 & 6 \\
\hline $\mathrm{C}_{8} \mathrm{OH}_{7}{ }^{+}$ & $-\mathrm{CNO}_{2} \mathrm{H}_{3} \mathrm{I}_{2}$ & 119.0491 & 119.0497 & 5 \\
\hline $\mathrm{C}_{7} \mathrm{OH}_{7}{ }^{+}$ & $-\mathrm{C}_{2} \mathrm{NO}_{2} \mathrm{H}_{3} \mathrm{I}_{2}$ & 107.0490 & 107.0497 & 7 \\
\hline
\end{tabular}


Fig. S1. A control experiment of the isolated ion of $[\mathrm{M}+\mathrm{H}]^{+}$at $\mathrm{m} / \mathrm{z} 433.87$ to that corresponding to Fig. 2a, with both IR and UV lasers off.

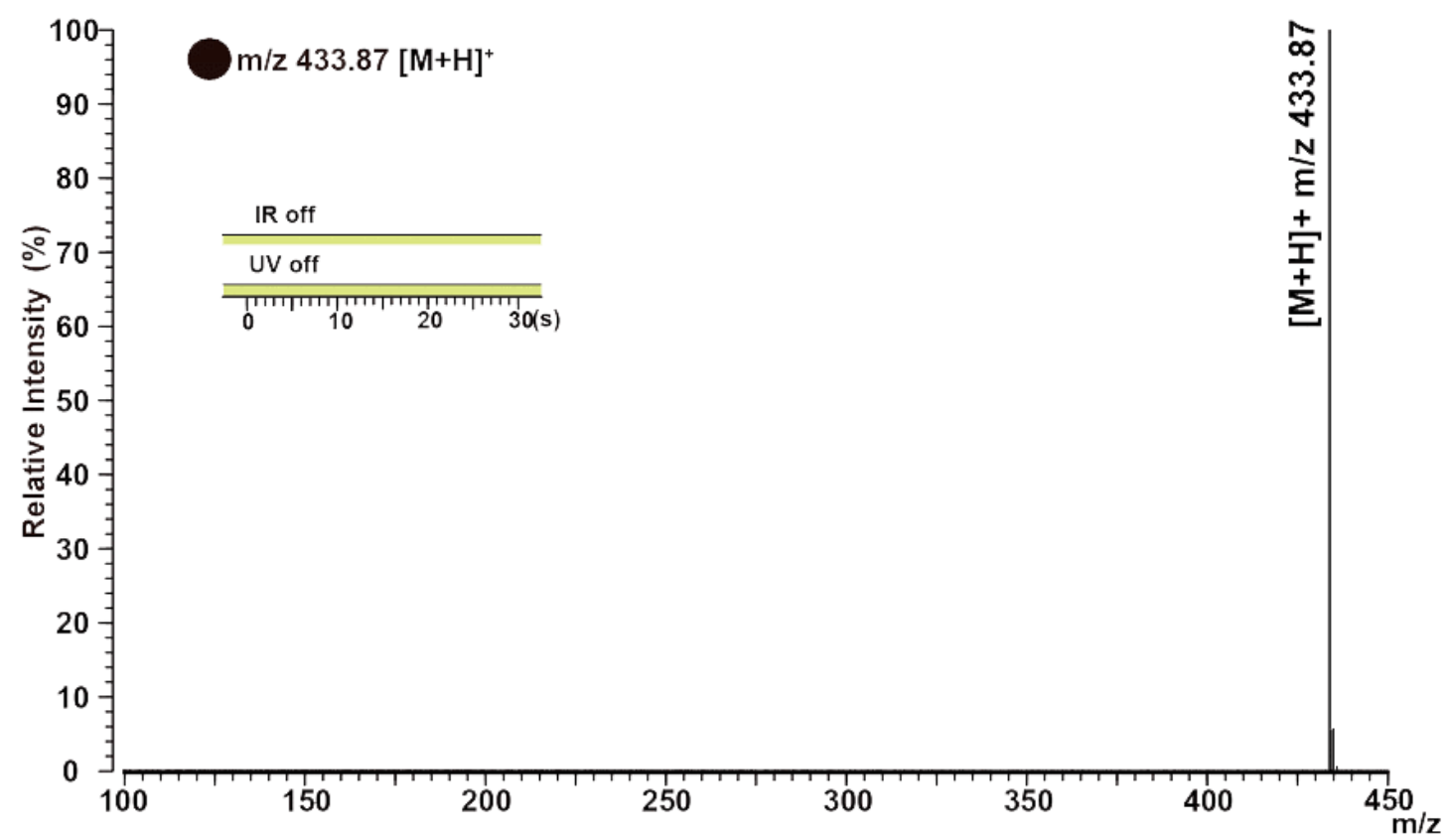


Figure S2 Photodissociation mass spectra of $[\mathrm{M}+\mathrm{H}]^{+}$at $\mathrm{m} / \mathrm{z}$ 433.87, generated by UV-first sequential irradiation of both IR and UV beams, in which the trigger of the UV laser is (a) no, (b) $5 \mathrm{~s}$, (c) $10 \mathrm{~s}$, (d) $15 \mathrm{~s}$ and (e) $18 \mathrm{~s}$ delay to that of the IR laser.
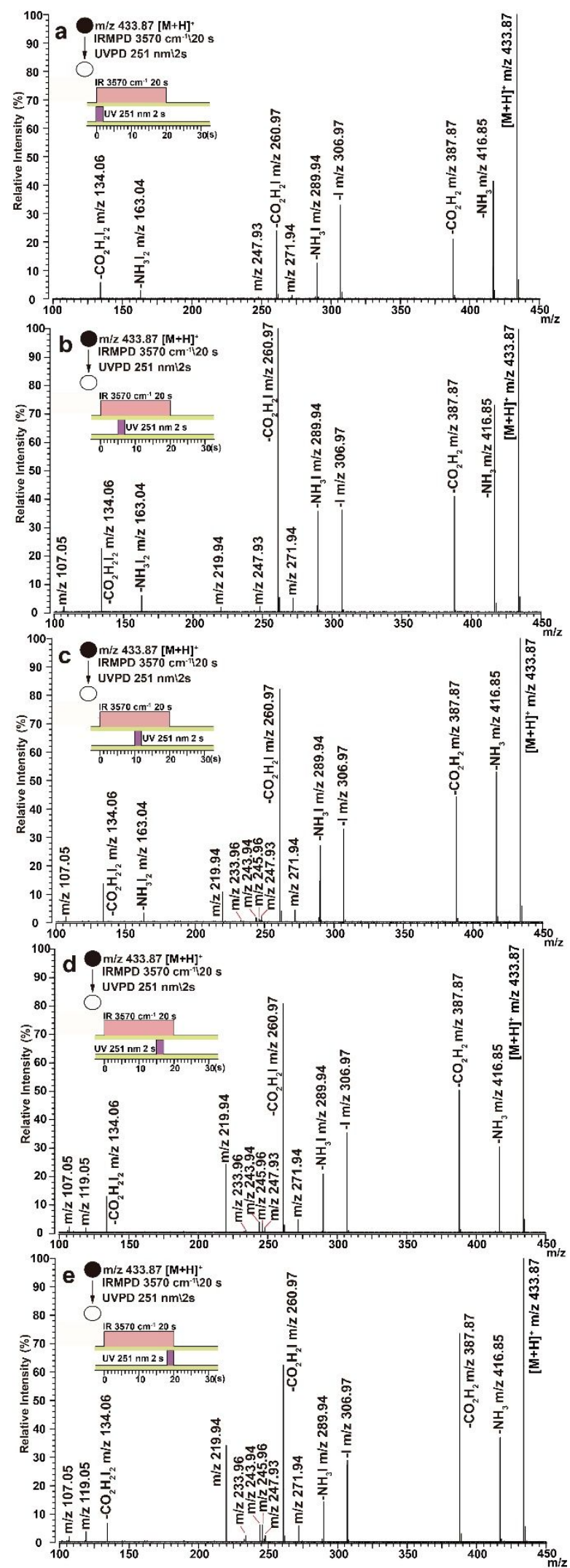
Figure S3 Relative intensities of different fragment ions generated in different sequential experiments: (a) ions at $\mathrm{m} / \mathrm{z} 416.85$ and 387.87 , which can be generated by IRMPD; (b) ions at m/z 306.97, 289.94, 261.97 and 134.06; which can be generated by UVPD; (c) ions at $\mathrm{m} / \mathrm{z} 163.04$, which was generated by the IR irradiation of the UVPD fragment ions; (d) ions at $\mathrm{m} / \mathrm{z}$ 245.96, 243.94, 233.96, 119.05 and 107.05, which were generated by the UV irradiation of the IRMPD fragment ions; (e) ions at $\mathrm{m} / \mathrm{z} 219.84$, which was also generated by the UV irradiation of the IRMPD fragment ions; and (f) ions at $\mathrm{m} / \mathrm{z} 271.94$ and 247.93, which can be generated by both processes. Among these results, the curves with typical nonmonotonic declines might indicate the existence of two or more pathways for their generation.
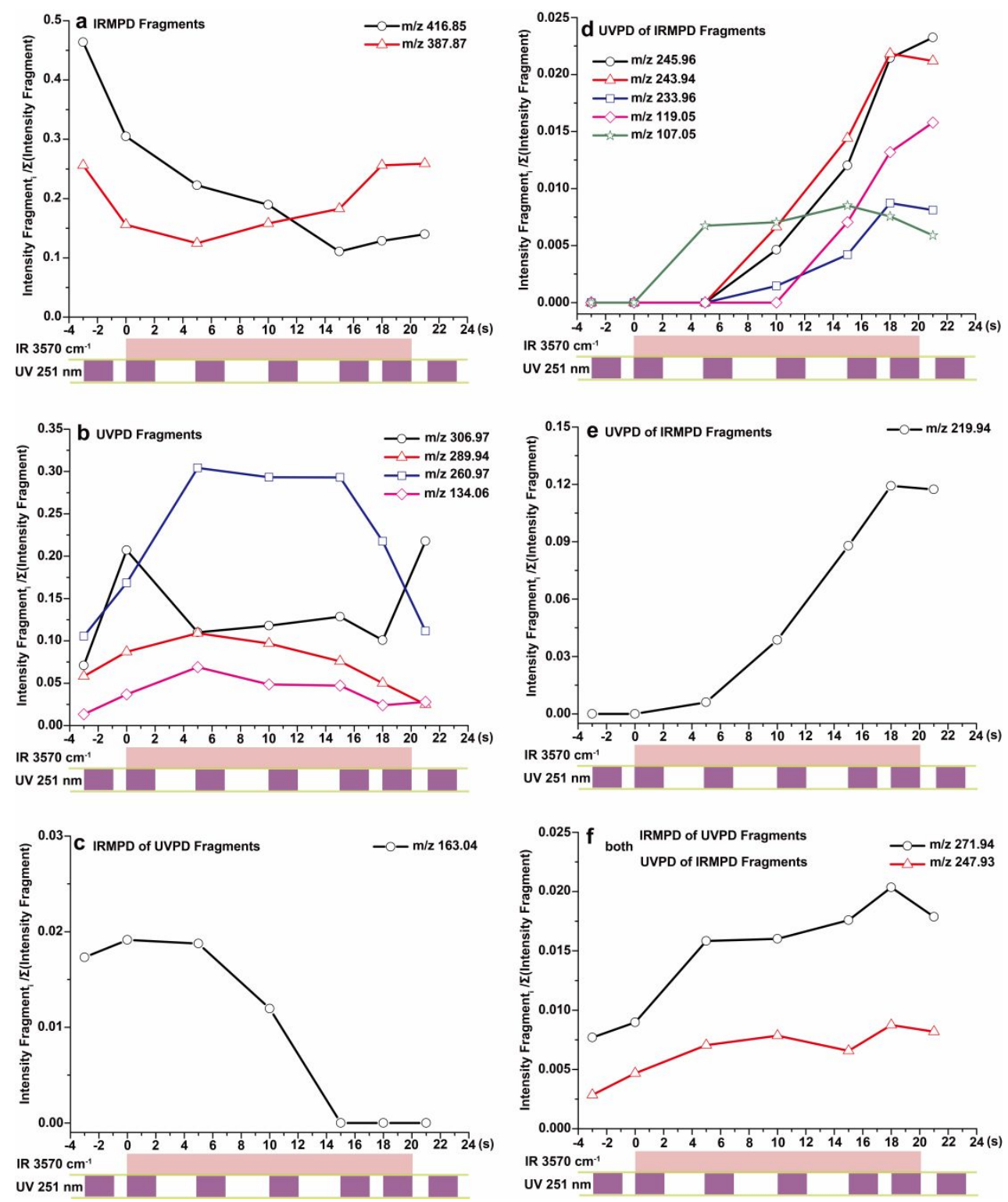
Figure S4 Top-down mass spectra of [Ubiquitin $+11 \mathrm{H}]^{+}$, generated by the irradiation of (a) IR laser at $3370 \mathrm{~cm}^{-1}$, (b) UV laser at $213 \mathrm{~nm}$ and (c) a combination of the IR at UV laser.

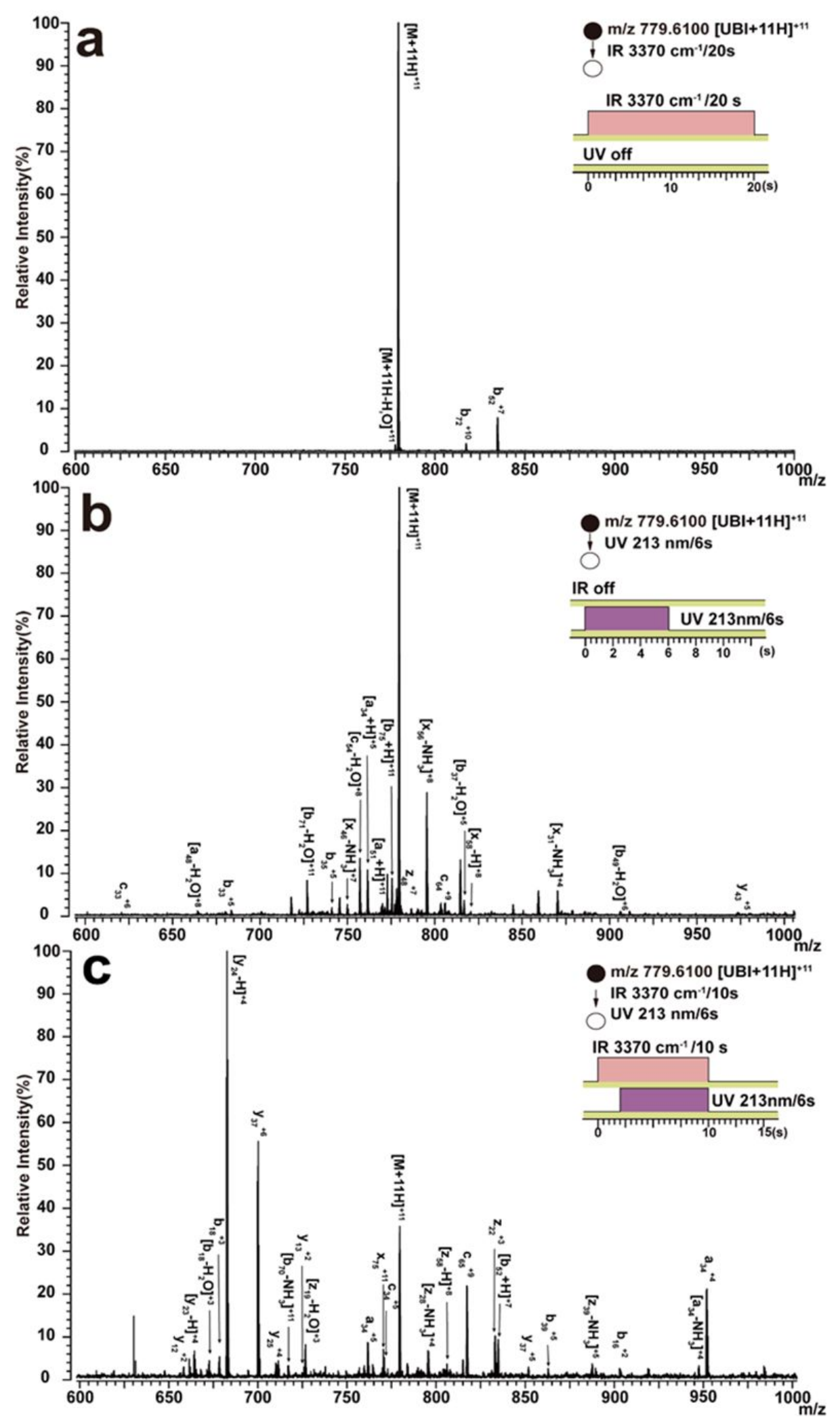


Figure S5 (a) The whole ESI mass spectrum without isolation; (b) the isolation ion of $[\mathrm{M}+\mathrm{H}]^{+}$at $\mathrm{m} / \mathrm{z} 433.87$; (c) the IRMPD mass spectrum of $[\mathrm{M}+\mathrm{H}]^{+}$obtained at 3570 $\mathrm{cm}^{-1}$ with an irradiation time of $30 \mathrm{~s}$; (d) the isolated fragment ion of $\left[\mathrm{M}+\mathrm{H}-\mathrm{NH}_{3}\right]^{+}$at $\mathrm{m} / \mathrm{z}$ 416.85; (e) the $251 \mathrm{~nm}$ UVPD mass spectrum of the selected IRMPD fragment ion at $\mathrm{m} / \mathrm{z} 416.85$, resulting an $\mathrm{MS}^{3}$ spectrum; (f) the isolated fragment ion of $\left[\mathrm{M}+\mathrm{H}-\mathrm{C}_{3} \mathrm{NO}_{2} \mathrm{H}_{5} \mathrm{I}\right]^{+}$at $\mathrm{m} / \mathrm{z}$ 219.94; (g) the $251 \mathrm{~nm}$ UVPD mass spectrum of the fragment ion at $\mathrm{m} / \mathrm{z} 219.94$, resulting an clear $\mathrm{MS}^{4}$ spectrum.

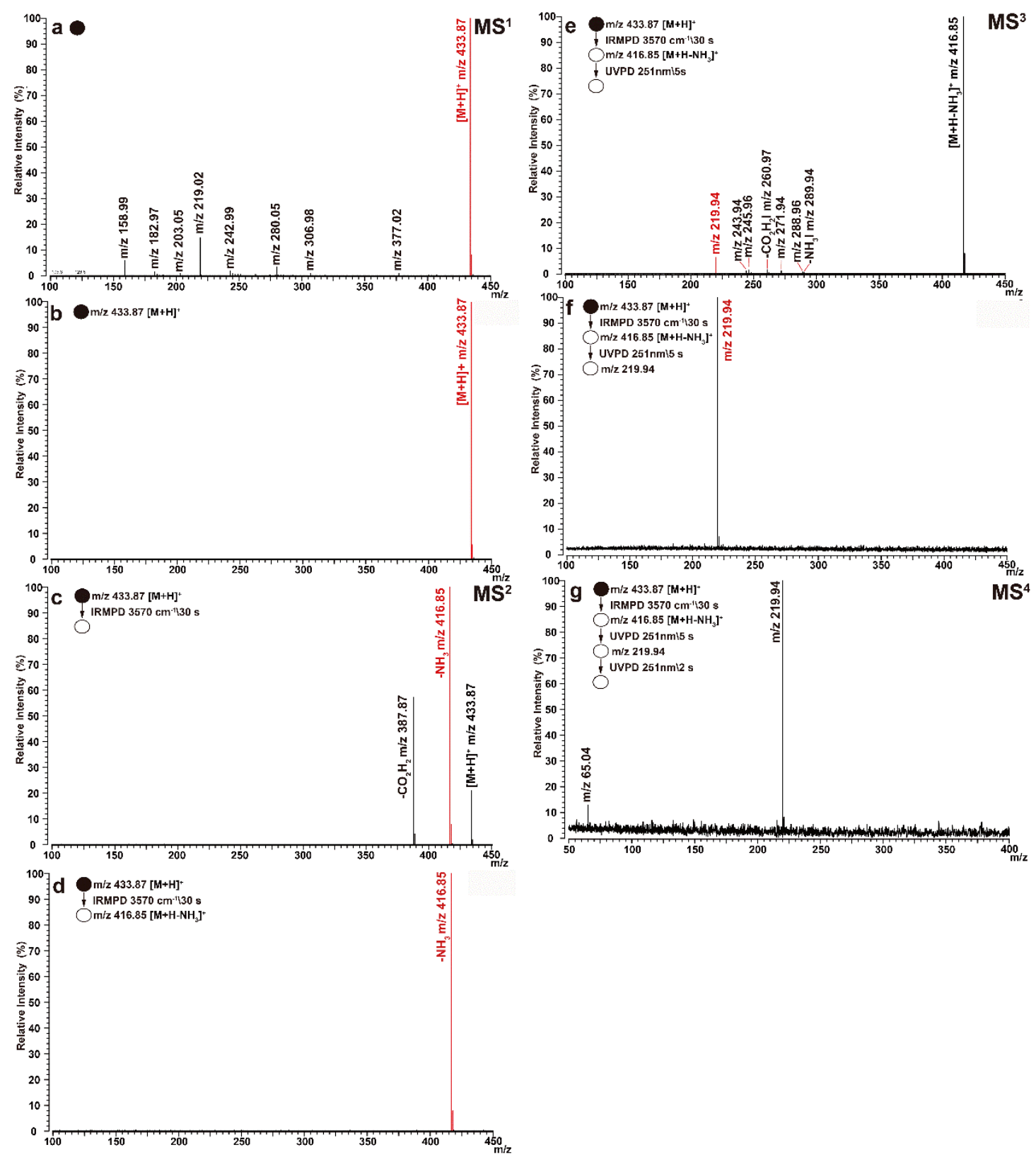

